\title{
Teenage mothers' knowledge \\ of sex education in a general hospital of the Umtata district \\ to
}

\section{Williams \\ B Cur (Hons) \\ University of Transkei}

\&

TR Mavundla PhD

University of Transkei

\section{"lack of information about}

sex leads to sexual

dysfunction, teenage

pregnancy, sexual abuse and

sexually transmitted

diseases."

\section{abstract}

There has been growing concern about the increase in teenage pregnancies in relation to the teenagers' knowledge of human sexuality and the impact sex education has on these teenagers in both the urban and rural areas. The aim of the study was to assess the knowledge of sex education and the health beliefs of teenagers with regard to teenage pregnancy.

A descriptive study was conducted in the Umtata district of the Eastern Cape. The sample involved 42 teenage mothers drawn from local rural and urban areas attending a Well Baby Clinic at Umtata General Hospital. A questionnaire was used as the method of data collection. Data analysis was done by a software package called SAS.

The study revealed that teenagers receive almost no sex education from health personnel and only a little from their parents. The study also revealed that most of these teenagers live with their mothers only instead of both parents. It also became clear that unsafe or unprotected sexual behaviour was practised by these teenagers although teenagers supported the idea of their partners using condoms.

The most common problem resulting from teenage pregnancy, as indicated from the study results, was the financial burden on parents and lost educational opportunities by the girls. In the recommendations the parents' involvement in sex education and the improvement of recreational facilities for both urban and rural areas are highlighted. In conclusion, the study has shown the need for more efforts to solve the problem of inadequate sex education and to change the health beliefs of teenagers.

\section{introduction}

Teenage health issues are a relatively new feature in society, since teenagers are generally regarded as having good health and strong physiques (WHO, 1990:23). This perception about teenagers means that there is more emphasis on maternal and child health care services mainly targeted at groups such as expectant mothers and children under the age of five years. As a result, teenagers are poorly accommodated in the above health services because some of them are still at school and others fall into the category of mothers (Williams, 1995:1).

Sex education and counselling on sexual problems for teenagers are part of a total health care strategy for this category of people. Lack of information about sex leads to sexual dysfunction, teenage pregnancy, sexual abuse and sexually transmitted diseases (Searle, Brink \& Grobbelaar, 1989:347).

It is estimated that more than $80 \%$ of the population supports school sex educa- tion. Though sex education is considered legal in most countries, many sex educators are hesitant to include all topics of sex related issues. They would rather put more emphasis on anatomy and physiology out of fear and the controversy associated with sex issues (Miller, 1992:352).

\section{problem statement}

In the past few years, schools in the Umtata district have not been providing sex education because of technical problems (Williams, 1995:3). The Umtata General Hospital in the Eastern Cape is experiencing shocking numbers of teenage pregnancies as revealed by a study conducted on sexuality among school girls in the Transkei region (Buga, Amoko \& Ncayiyana, 1995:6)

Complaints from principals of the schools around Umtata have been pouring into the school health nurses' office. The principals presented documented 
evidence of problems facing teenagers in the local schools of the Umtata district. The problems range from physical changes to pregnancy and sexual relations (Williams, 1995:5).

\section{research question}

What knowledge and opinions do teenage mothers have regarding sex issues?

\section{objectives}

- To assess the knowledge and opinions of teenage mothers who attend a Well Baby Clinic at Umtata Hospital about sex education

- To determine whether teenage mothers were given sex education prior to pregnancy

- To make recommendations appropriate for the role of the community health nurse in the prevention of teenage pregnancies

\section{definition of terms}

The following definitions could be made in order to have a clear understanding of the study:

\section{TEENAGER}

This is a young person in his or her teens. This phase of psychosexual development starts at about $11-13$ years and continues up to 19 years.

\section{SEX EDUCATION}

This refers to education or guidance which makes teenagers aware of their bodies, particularly in respect of reproductive anatomy and physiology. It is a part of comprehensive life skills training which prepares individuals for emotional and physical changes they will be going through.

\section{theoretical framework}

The study was based on a health belief model as proposed by Redman (1984). In view of the assumptions of the health belief model, teenagers are expected to take responsible, informed decisions when they believe that they are susceptible to pregnancy and sexually transmitted diseases. When they perceive these problems to have serious effects on their lives, they will use safer sex methods to reduce the likelihood of the occurrence of these problems.

\section{literature review}

The problems encountered by the youth are coupled with the critical situation of health services in the rural Eastern Cape. These problems include scarce facilities, medical supplies and resources.

Several studies have identified a series of circumstances in general that place teenagers in a high risk category. These include not only the individual factors but those of the family, institutions and the entire society (Buga, Amoko \& Ncayiyana, 1995:6).

The worst problem facing teenagers is peer group pressure (Oskowitz, 1993:62; Koyana, 1995:2). Girls are not strong enough to resist the pressure put on them by their peers. Though they may not be ready to sleep with boys, they find themselves yielding because they are ridiculed and sometimes ostracised by other girls who call them "nuns". Some are intimidated and told that if they do not engage in sexual in tercourse they will become sick or crazy. At the same time nothing is mentioned to teenagers about safe sex.

Socio-economic factors also play a major role in dictating the behaviour of teenagers. These factors may be a lack of housing and recreational facilities in the villages. Time and energy are thus channelled to sexual activities. On the other hand, teenagers live far from schools with little or no pocket money most of the time. As a means of earning some income, they engage in sexual activities with older men for money (Koyana, 1995:3).

Sex education has been a source of great controversy in some communities where people fear that providing sex education will encourage and promote sexual activity and promiscuity among teenagers who are not yet involved in these activities (Oskowitz, 1993:64). As a result, teenagers are often confused and do not know where to go for advice and counselling because they are regarded as too young to be treated by the practitioners and too old to seek advice from paediatricians (WHO, 1990:22).

Teenagers have expressed a fear of approaching their parents about contraceptive methods. The same girls are afraid to lose their boyfriends. If they do not comply with the demand for sex there is greater risk of their being dumped by their boyfriends (Koyana, 1995:3).

Parents themselves are in a dilemma between upholding the traditional and cultural values with religious beliefs at the expense of their daughters. Some parents are unhappy that their daughters may be taught sensitive sexual matters by people who do not have the same home values.

One should not forget the consequences of teenage pregnancies. One consequence is that teenage girls turn to illegal abortions which often result in complications and even death. The majority of these girls are still biologically immature for effective childbirth. Prenatal care is usually inadequate as compared to that given to adult women (WHO, 1990:22).

Secondly, teenage fathers at times experience the same emotional and psychological problems as teenage mothers. Problems such as unemployment poor accommodation and poor health are common (WHO, 1990:23)

Thirdly, teenage mothers may end up being single parents because there is less chance of marriage. Single mothers in particular need support throughout their lives in bringing up their babies (Miller, 1992:353).

\section{research design and methodology}

A descriptive design was chosen by the researchers, since the researchers were interested in identifying sex education received or given to teenagers and the health beliefs of teenagers regarding teenage pregnancy and sexually transmitted diseases.

The population consisted of teenage mothers from the Umtata district who had visited the Well Baby Clinic. One requirement was that the babies they were carrying had to be their first babies.

A sample of 42 respondents was drawn from the population of teenage mothers A systematic random sampling technique was chosen where every third teenage mother was selected and re quested to participate in the study.

\section{instrumentation}

The two constructs of the study were sex education and the health beliefs of teenagers. Since there were no existing tools to measure the two constructs adequately, a new tool was constructed by the researchers.

Sex education: The tool contained questions that assessed whether sex education was given to teenagers prior to pregnancy. It also contained statements/questions that examined the status of the person who gave sex education and their relationship to the teenagers.

Health beliefs: The health beliefs in this tool were measured as influenced by the sex education given. This construct was measured by the following concepts in the tool:

$\begin{array}{ll}\text { - } & \text { Attitudes } \\ \text { - } & \text { Opinions } \\ \text { - Knowledge }\end{array}$


- Sex practices with regard to the prevention of teenage pregnancy and the spread of sexually transmitted diseases

Structured questionnaires were used by the researchers to collect data from the teenage mothers. The questions included both open-ended and closed questions. The questions were formulated to find out about the knowledge, opinions and attitudes on sex education in relation to the increasing rate of teenage pregnancies. They also assessed the effectiveness of the sex education programme for school girls in the areas around Umtata.

\section{Reliability and validity}

The reliability test method used was divided in half at the time of scoring the results of the pretest. The two halves of the test produced approximately equal scores.

The suitable measuring aspect of validity in this study was content validity. It was imperative to consult experts on teenage sexuality. The researchers referred the instrument to obstetricians, community health nurses, school health nurses, health educators and researchers, who judged the content of the questionnaire in relation to variables that it was supposed to measure. The theoretical constructs were found to be adequately measured. They were further found to measure the construct of sex education.

\section{ethical consideration}

It was important for the researchers to obtain informed consent from the participants before conducting the study. A letter was distributed to each respondent explaining the purpose of the study and the conditions under which the respondent had to participate in the study. Permission to conduct the study was also obtained from the matron of the Umtata General Hospital where the study was conducted. Privacy during the gathering of information was ensured. The anonymity of respondents was also guaranteed by the researchers in that names of the respondents were not required. Confidentiality of the information given was also guaranteed by the researchers.

\section{research setting}

The research was conducted at the Umtata Hospital's Well Baby Clinic. The

age distribution of respondents

\begin{tabular}{|c|c|c|c|}
\hline FREQUENCY & PERCENTAGE & $\begin{array}{c}\text { CUMULATIVE } \\
\text { FREQUENCY }\end{array}$ & $\begin{array}{c}\text { CUMULATIVE } \\
\text { PERCENTAGE }\end{array}$ \\
\hline 1 & 2.4 & 1 & 2.4 \\
\hline 3 & 19.0 & 9 & 21.4 \\
\hline 42 & 78.6 & 42 & 100.0 \\
\hline
\end{tabular}

Umtata Hospital is situated in an urban area but also offers health services to rural areas in the district. The clients seen were drawn from rural, semiurban and urban areas. All data gathered were a $n$ a I y s e d through a computer software package, the SAS program.

\section{data analysis and findings sample description}

Of the 66 questionnaires that were distributed to the respondents, 42 were completed and returned. The sample consisted of teenage girls who had become pregnant for the first time. The teenage mothers were selected when visiting the Well Baby Clinic for immunisation of their babies.

Age of respondents: The majority of the pregnant girls were between the ages of 17 and 19 at the time of the study. About $19 \%$ $(\mathrm{N}=8)$ were between the ages of 14 and 16 and there was only one respondent who did not respond. See table 1

Grade: A small percentage, i.e. $9,5 \%(\mathrm{~N}=4)$, were in the lower grades, i.e. less than grade 7 . The majority of girls, i.e. $50 \%(\mathrm{~N}=21)$, were in grades 8-10. There were no differences identified in terms of the grades between urban and rural girls.

Area of residence: Though the hospital is in an urban area, it serves clients

\section{table 3 religious affiliation}

\begin{tabular}{|l|c|c|}
\hline $\begin{array}{c}\text { RELIGIOUS } \\
\text { AFFILIATION }\end{array}$ & FREQUENCY & PERCENTAGE \\
\hline No response & 1 & 2.4 \\
\hline Roman Catholic & 11 & 26.2 \\
\hline Protestant & 15 & 35.7 \\
\hline AIC & 18 & 19.0 \\
\hline Other & 7 & 16.7 \\
\hline Total & 42 & 100 \\
\hline
\end{tabular}

Family structure: Family structure was mostly nuclear, mothers being the people available to the majority of teenagers $(57,1 \%(N=24))$. Some of the teenagers lived with both of their parents $(26,2 \%(N=11))$. About $16,7 \%$ lived with adults other than their parents. 
table 4 teenagers who had sexual intercourse

\begin{tabular}{|l|c|c|}
\hline $\begin{array}{c}\text { AGE WHEN } \\
\text { FIRST HAD } \\
\text { SEXUAL } \\
\text { INTERCOURSE }\end{array}$ & FREQUENCY & PERCENTAGE \\
\hline No percentage & 4 & 9.5 \\
\hline $11-14$ years & 8 & 19.0 \\
\hline $15-17$ years & 29 & 69.0 \\
\hline 18 yrs and over & 1 & 2.4 \\
\hline Total & 42 & 100 \\
\hline
\end{tabular}

Age when first had boyfriend: The majority of the respondents had their first boytriend at the ages of $15-17(73,8 \%)$, $14,29 \%$ had their first boyfriend between the ages of 11 and 14 and only $11,90 \%$ had their first boyfriend at the age of 18 and over.

Age when first had sexual intercourse: A total of $69 \%(N=29)$ of the respondents started having sexual intercourse at the ages of 15-17. It is important to study these age groups because statistics have shown that they are at the highest risk of teenage pregnancy, although the age group $11-14$ years $(N=8)(19,05 \%)$ should also be considered. See table 4 .

Teenagers who received sex education: The majority of teenagers received sex education $(59,5 \%), 31 \%$ did not receive sex education and $9,5 \%$ did not respond to this question.

Source of information: Among the teenagers who had received sex education, the majority received it from their parents, i.e. $21,4 \%(N=9)$. Teachers $(16,7 \%$ $(\mathrm{N}=4))$ and the church $(21,4 \%(\mathrm{~N}=9))$ also seem to be common sources of sex education.

Education on contraception: Some

\section{table 5 use of contraceptives}

\begin{tabular}{|l|c|c|}
\hline $\begin{array}{c}\text { USE OF } \\
\text { CONTRACEP- } \\
\text { TIVES }\end{array}$ & FREQUENCY & PERCENTAGE \\
\hline No response & 1 & 2.4 \\
\hline Yes & 11 & 26.2 \\
\hline No & 30 & 71.4 \\
\hline Total & 42 & 100 \\
\hline
\end{tabular}

The type of method used: Among those who used contraceptives, the most commonly used method was the pill $(19 \%$ $(N=8)$ ) and abstinence. Only $2,4 \%$ $(\mathrm{N}=1)$ used condoms.

5. Socio-economic status is affected 6. The baby may be abandoned by the mother and left with grannies who are less capable of looking after the baby 7. Unacceptance of the pregnant girl by the parents

8. Inability to clothe and feed the baby, with the concomitant results

9. Less opportunities for good paying jobs

10. Teenage pregnancy leads to overpopulation and a cycle of poverty for the less privileged girls

Use of contraception: The majority of teenagers did not use any contraceptive method $(71,4 \%(N=30))$. See table 5 .

Opinions on the use of condoms by their partners: Although $26,2 \%$ $(N=11)$ were not sure, the same number $(26,2 \%$ $(\mathrm{N}=11))$ strongly agreed with the use of condoms by their boyfriends and $21,4 \%(\mathrm{~N}=9)$ agreed with the idea of partners using condoms. About 26,2\% $(\mathrm{N}=11)$ totally disagreed with the use of condoms by their partners.

\section{table 6 the possibility of becoming pregnant if the teenagers had had knowledge of sexual matters}

\begin{tabular}{|l|c|c|}
\hline $\begin{array}{c}\text { POSSIBILITY } \\
\text { OF BECOMING } \\
\text { PREGNANT }\end{array}$ & FREQUENCY & PERCENTAGE \\
\hline No response & 2 & 4.2 \\
\hline Yes & 4 & 9.5 \\
\hline No & 27 & 64.3 \\
\hline Uncertain & 9 & 21.4 \\
\hline Total & 42 & 100 \\
\hline
\end{tabular}

Opinions on teenage pregnancy as a social problem: All the respondents agreed that teenage pregnancy is a social problem. Some did not give reasons why they said so. Among the many reasons given as to why teenage pregnancy is a social problem were the following:

1. Financial inconvenience to parents

2. Teenage fathers not paying lobola or supporting the child and or denying the child 3. Teenage mothers too young to bring up babies 4. Schooling is delayed agers were uncertain if they would have become pregnant if they had had knowledge of sexual matters $(64,3 \%(\mathrm{~N}=27))$. However, $21,4 \%(N=9)$ were positive that they would not have become pregnant. See table 6 .

\section{Support for inclusion of sex education} in school syllabi

The feeling of many respondents was that sex education should be included in the school curriculum $(66,7 \%(\mathrm{~N}=28))$. About $23,8 \%(\mathrm{~N}=10)$ did not support this view and $9,5 \%(\mathrm{~N}=4)$ did not respond to this question.

\section{Opinions on safe sex}

The use of condoms was felt by many teenagers as the safest sex method $(42,9 \%(N=18))$. Some other opinions were also supported, e.g. only one partner $(14,3 \%(N=6))$. Some teenagers supported the combination of all meas- 
ures $(21,4 \%(\mathrm{~N}=9))$.

Premarital sex to be discouraged: Teenagers themselves felt that they should be discouraged from having premarital $\operatorname{sex}(38,1 \%(\mathrm{~N}=16))$.

Active involvement of teenagers in the teenage pregnancy prevention programme: The feeling of the teenagers is that their peers should be actively involved in the teenage pregnancy prevention programmes $(73,8 \%(N=31))$. Some of the respondents even gave the reasons for their support, such as "the fellow teenagers know exactly the pressures and problems experienced by teenagers".

Those who were not in favour of teenagers being actively involved in the programmes did not trust the fellow teenagers to have expert knowledge in dealing with youth problems, as those teens would also be in the same boat

\section{discussions}

The study revealed that most teenagers live with their mothers only. It also appeared that teenagers commence their sexual relations and sexual intercourse at the average age of between 15 and 17 while they are in the lower grades, e.g. grades 8-10. Some girls start having sexual intercourse even earlier than that. Though parents are the largest group to give sex education, it seems that this information is too inadequate to equip the teenagers to face the pressures with regard to sexual matters. This is closely linked to the communication problem between teenagers and parents. It was also shocking and embarrassing in the study to note how the health personnel have not been of help to these teenagers during this era of primary health care orientation, even though health education should be addressing the basic local needs and problems.

The study also revealed the rate of unprotected sexual behaviour among teenagers. Only $2,4 \%(N=1)$ had used condoms as a form of contraceptive. This raises concern not only about the teenage pregnancy rate, but also about sexually transmitted diseases, especially the transmission of HIV among all sexually active people.

Teenagers, though, regard the use of condoms as the safest sex method. One wonders whether there are some other reasons why they are not using condoms when they perceive them as the safer method of contraception. Their educators may not be presenting condoms as an acceptable and realistic method of contraception. Teenagers seem to support the idea of their boyfriends using condoms, but girls as a weaker sex seem to yield to pressure, even if they know what is good for them, and they sacrifice their rights in the name of love. Black African women are culturally oriented to accept that it is the Creator's will for a woman to be inferior to a man and as such they cannot totally reject and oppose what a man thinks is good.

The teenagers are equally optimistic and approve the inclusion of sex education in the school curriculum. There is a concern in this regard in South Africa because of the political history of sex education in schools. The different Houses of Parliament that existed before 1994 had different approaches to this matter. Some groups had already started and some were just starting to provide sex education in schools, e.g. the House of Assembly (for whites) Cape Education Department had started, the House of Representatives was starting and House of Delegates still had some culture and religion problems (Van der Elst, 1993:13). The Department of Education has to consider these aspects because blacks were totally excluded. Sex education programmes were and still are non-existent, yet blacks form the largest population group with a higher rate of teenage pregnancy and infant mortality.

Teenage girls also support the idea of discouraging premarital sex. It has been revealed by research that if teenagers wait before engaging in sexual intercourse too soon, they have the opportunity for emotional, intellectual and physical development.

\section{recommendations}

The recommendations are dealt with in three sections:

\section{Nursing practice}

A strategy for involving parents in sex education should be developed. This will help them develop a sense of confidence and responsibility within family structures with regard to sex education.

Improving and establishing recreational facilities for different sports in both urban and rural areas is very important for teenagers so that they have somewhere to spend their leisure time. This may prevent them from engaging in sexual activities.

Budgetary arrangements by the government of the Eastern Cape should be planned to meet the financial costs of buying equipment such as videos and other educational material. Such equipment may assist school health nurses and teachers in educating the youth about sexuality. All this necessitates government's commitment and vision at a higher level to support and actively participate in addressing the issue of teenage pregnancies.

\section{Nursing education}

It is recommended that community health nurses working at clinics and in schools in the area where the study was conducted receive intensive orientation courses on sex education. They should follow a special programme which will be applicable to the entire Eastern Cape. Such a programme should be able to evaluate its impact on the targeted age category.

\section{Further research}

After the data in this study were analysed, it became clear that there is still a need for further research on various aspects of the problem. These aspects are as follows:

The development of a strategy for involving parents in sex education

There is a great need for involving parents in sex education programmes. Therefore, future research should be conducted with the aim of developing and testing a strategy of this nature.

\section{The development of a sex education programme}

A sex education programme for adolescents staying in both rural and urban areas of the Eastern Cape should be developed and tested. This programme may be part of the school curriculum or it may be an enriching subject offered to the youth. It should contain not only the knowledge needed by the youth about sexual matters, but it should also empower the youth with effective skills to make appropriate decisions about sexual matters. This programme should make them sensitive to the problems associated with teenage pregnancy, and it should equip the youth with life skills that will help them go through their teenage years without becoming casualties of the unfair youth pressures.

\section{conclusion}

The study has revealed the extent of the problem of teenage pregnancy in the rural and urban areas of Umtata, and in an already overpopulated and underdeveloped area such as Transkei in the Eastern Cape. 


\section{bibliography}

BUGA, A.B., AMOKO, D.H.A. and NCAYIYANA, D.J. 1995. Teenage pregnancy at Umtata. Book of Abstracts 10th Anniversary : Faculty of Medicine and Health Sciences, UNITRA: Umtata.

KOYANA, N. 1995. Living and working with young women today. Handout paper presented at the TRAUW Conference. UNITRA: Umtata.

MILLER, D.F. 1992. Dimensions of Community Health. Wmn Brown Publishers: Dubuquc.

OSKOWITZ, B. 1993. Critical issues. Sexuality education a value sensitive approach. 44:61-72.

REDMAN, B.K. 1984. The process of patient education. Mosby Company: St Louis.

SEARLE, C., BRINK, H.I.L. \& GROBBELAAR, W.C. 1989. Aspects of Community Health. King Edward VII Trust: Cape Town.

VAN DER ELST, E.E. 1993. A Sexuality Education Training Programme for Guidance-Counsellor Trainees: A Qualitative Inquiry and Evaluation. University of Cape Town: Cape Town.

WHO. 1990. Teenage pregnancy in New York. WHO Women and Health Magazine. April-May :20-21.

WILLIAMS, G.X. 1995. The impact of sex education on health beliefs of teenage mothers attending a Well Baby Clinic at Umtata General Hospital. Honours Degree Dissertation. University of Transkei: Umtata. 